\title{
Spike synchronization is population specific in the respiratory pattern generator David M Baekey ${ }^{1}$, Thomas E Dick¹,2 and Roberto F Galán*2
}

\author{
Address: ${ }^{1}$ Department of Medicine, Case Western Reserve University, Cleveland, Ohio 44106, USA and ${ }^{2}$ Department of Neurosciences, Case \\ Western Reserve University, Cleveland, Ohio 44106, USA \\ Email: Roberto F Galán* - rfgalan@case.edu \\ * Corresponding author
}

from Eighteenth Annual Computational Neuroscience Meeting: CNS*2009

Berlin, Germany. 18-23 July 2009

Published: 13 July 2009

BMC Neuroscience 2009, I0(Suppl I):P248 doi:I0.I I86/I47|-2202-I0-SI-P248

This abstract is available from: http://www.biomedcentral.com//47I-2202/I0/SI/P248

(c) 2009 Baekey et al; licensee BioMed Central Ltd.

\section{Introduction}

Breathing accounts for only a small fraction of basal metabolism and its motor pattern is highly efficient mechanically [1]. While this view is widely accepted, no one understands whether this property is malleable and whether it can be utilized to attenuate respiratory failure as well as to facilitate weaning from artificial ventilation. Several factors influence muscle force including firing rate and recruitment of pre-motor and motoneurons (MNs), which increase energy consumption. Another factor is the synchronization of spikes of MNs, which increases muscle force in an energy efficient manner, preserving rather than increasing the firing frequency of active motor units. In line with Otis's findings, we hypothesized that the respiratory control network uses synchrony to generate an efficient inspiratory pattern, minimizing the work of diaphragm contraction, chest wall expansion and lung inflation.

\section{Methods}

To test our hypothesis, we recorded ensembles of respiratory neurons in perfused in situ preparations (SpragueDawley/Harlan rats) that produce a ramping breathing pattern spontaneously (for details on preparation, see [2]). A 16-channel microelectrode array placed 8 tungsten electrodes (10-12 M $\Omega$ ) on either side of the spinal cord or brainstem. The design allowed for simultaneous bilateral recording of spinal motor or brainstem pre-motor neurons, and those of the pre-Bötzinger complex. The independent depth adjustment of each electrode optimized the yield of isolated high signal-to-noise activity. In a typical experiment, we are able to record an ensemble of 6 to 16 neurons. Spike-synchrony between neurons was calculated as reported somewhere else [3].

\section{Results}

Simultaneous recordings from neurons in and around the rostral-ventral respiratory group (inspiratory pre-motor area) have been processed and converted to spike trains in order to assess their temporal relationships. While expiratory and non-respiratory modulated cells show a low level of coordination, the pre-motor inspiratory cells exhibit significant spike-synchrony levels in eupneic-like breathing conditions.

\section{Acknowledgements}

This work has been supported by the American Heart Association (SDG $0735037 \mathrm{~N}, \mathrm{DMB})$, the National Institutes of Health (HL-0803 I8 \& HL007887, TED), and The Mount Sinai Health Care Foundation (RFG).

\section{References}

I. Otis AB: The work of breathing. Physiol Rev 1954, 34:449-458.

2. Baekey DM, Dick TE, Paton JF: Pontomedullary transection attenuates central respiratory modulation of sympathetic discharge, heart rate and the baroreceptor reflex in the in situ rat preparation. Exp Physiol 2008, 93:803-816.

3. Galán RF, Fourcaud-Trocmé N, Ermentrout GB, Urban NN: Correlation-induced synchronization of oscillations in olfactory bulb neurons. J Neurosci 2006, 26:3646-3655. 